\title{
A Recurrent BRCA2 Mutation Explains the Majority of Hereditary Breast and Ovarian Cancer Syndrome Cases in Puerto Rico
}

\author{
Hector J. Diaz-Zabala ${ }^{1}$, Ana P. Ortiz ${ }^{2}$, Lisa Garland ${ }^{3}$, Kristine Jones ${ }^{3}$, Cynthia M. Perez ${ }^{4}$, \\ Edna Mora ${ }^{5}$, Nelly Arroyo ${ }^{1}$, Taras K. Oleksyk ${ }^{6,7}$, Miguel Echenique ${ }^{8}$, Jaime L. Matta ${ }^{1}{ }^{1}$, \\ Michael Dean ${ }^{9}$ (D) and Julie Dutil ${ }^{1, *}$ \\ 1 Cancer Biology Division, Ponce Research Institute, Ponce Health Sciences University, Ponce, PR 00716-2348, \\ USA; diazhectorjoel@gmail.com (H.J.D.-Z.); narroyo@psm.edu (N.A.); jmatta@psm.edu (J.L.M.) \\ 2 Cancer Control and Population Sciences Program, Comprehensive Cancer Center, University of Puerto Rico, \\ San Juan, PR 00936-5067, USA; ana.ortiz7@upr.edu \\ 3 Cancer Genomics Research Laboratory, Leidos Biomedical Research, Inc., Frederick, MD 21702, USA; \\ garlandlr@mail.nih.gov (L.G.); kristine.jones@nih.gov (K.J.) \\ 4 Department of Biostatistics and Epidemiology, Graduate School of Public Health, University of Puerto Rico, \\ San Juan, PR 00936-5067, USA; cynthia.perez1@upr.edu \\ 5 Department of Surgery, School of Medicine, University of Puerto Rico and University of Puerto Rico \\ Comprehensive Cancer Center, San Juan, PR 00936-5067, USA; emora@cccupr.org \\ 6 Biology Department, Oakland University, Rochester, MI 48309-4454, USA; oleksyk@oakland.edu \\ 7 Department of Biology, University of Puerto Rico in Mayaguez, Mayaguez, PR 00681, USA \\ 8 Cancer Center, Auxilio Mutuo Hospital, San Juan, PR 00936-5067, USA; echeniquemm@gmail.com \\ 9 Laboratory of Translational Genomics, Division of Cancer Epidemiology and Genetics, \\ National Cancer Institute, Gaithersburg, MD 20877, USA; deanm@mail.nih.gov \\ * Correspondence: jdutil@psm.edu; Tel.: +1-787-840-2575
}

Received: 14 August 2018; Accepted: 26 October 2018; Published: 2 November 2018

\begin{abstract}
Breast cancer is the most common cause of cancer diagnosis in women and is responsible for considerable mortality among the women of Puerto Rico. However, there are few studies in Puerto Rico on the genetic factors influencing risk. To determine the contribution of pathogenic mutations in $B R C A 1$ and $B R C A 2$, we sequenced these genes in 302 cases from two separate medical centers, who were not selected for age of onset or family history. We identified nine cases that are carriers of pathogenic germline mutation. This represents $2.9 \%$ of unselected cases and $5.6 \%$ of women meeting National Comprehensive Cancer Network (NCCN) criteria for BRCA testing. All of the identified pathogenic mutations were in the $B R C A 2$ gene and the most common mutation is the p.Glu1308Ter (E1308X) mutation in BRCA2 found in eight out of nine cases, representing $89 \%$ of the pathogenic carriers. The E1308X mutation has been identified in breast and ovarian cancer families in Spain, and analysis of flanking DNA polymorphisms shows that all E1308X carriers occur on the same haplotype. This is consistent with BRCA2 E1308X being a founder mutation for the Puerto Rican population. These results will contribute to better inform genetic screening and counseling of breast and ovarian cancer cases in Puerto Rico and Puerto Rican populations in mainland United States.
\end{abstract}

Keywords: breast cancer genetics; $B R C A 1 / B R C A 2$; founder effect; Hispanic and Latino populations

\section{Introduction}

Pathogenic variants in the highly penetrant susceptibility genes BRCA1 and BRCA2 confer an increased lifetime risk of breast, ovarian and other cancers [1,2]. For women at high risk of developing breast cancer $(\mathrm{BC})$, risk reduction options include increased surveillance [3], chemoprevention [4,5] and 
prophylactic surgery [6,7]. Research has shown that women who are educated about their increased risk of breast cancer are more likely to engage in risk-reducing behaviors and early detection strategies such as monthly self-breast exam, physician visits, mammography and breast magnetic resonance imaging (MRI) screening [8]. In newly diagnosed cancer patients, BRCA testing also reportedly affects surgical decision-making [8-10]. BRCA testing in family relatives of identified carriers can discriminate between those at high risk and spare others from unnecessary risk-reducing options [8].

While most populations of Latin America and the Caribbean result from the admixture of ancestors from African, European and Native American origins, substantial heterogeneity has been observed within and across countries [11]. Such variability translates into distinct genetic architecture underlying diseases with a hereditary component. The prevalence of hereditary cancers attributed to pathogenic variants in the BRCA1 and BRCA2 genes in unselected BC patients from Latin America and the Caribbean varies from $1.2 \%$ in Columbia to $27.1 \%$ in the Bahamas [12]. As a result of founder effects, some populations have shown decreased genetic variability in the spectrum of $B R C A$ mutations observed, but others such as Argentina exhibit considerable diversity with fewer recurrent mutations [12].

In Puerto Rico, our previous work indicates that a few recurrent mutations may explain the majority of hereditary cancer cases [13]. However, this preliminary work relied on a limited sample size. The objective of the current study was to estimate the frequency of the BRCA mutations in a group of breast cancer patients unselected for age of onset or family history of cancer and identify the common pathogenic variants in this population. Understanding the genetic basis of hereditary cancers in a given population is essential for targeting screening, prevention strategies and clinical management of cancers that incorporate the unique features characterizing each population.

\section{Results}

\subsection{Characteristics of the Study Population}

The description of demographic, hormonal and clinical characteristics of the study population is presented in Table S1. All study participants had been previously diagnosed with BC but were not selected for age of onset or family history of breast or other cancers. Most of the study population was married (53.2\%) and of diverse socioeconomic status as indicated by a roughly equal proportion of participants with an education level of up to high school (40.2\%) and holding at least a bachelor's degree $(37.1 \%)$. In terms of hormonal and pregnancy history, most women had a menarche before 13 years of age $(56.9 \%)$, had a history of pregnancy $(88.8 \%)$ with one to two children $(44.7 \%)$, and were currently undergoing or had undergone menopause (67.2\%). Approximately forty percent had had their breast cancer diagnosis at or before the age of 50 years. The most common tumors were ductal invasive carcinomas (71.1\%), smaller than $2 \mathrm{~cm}(64.4 \%)$ and negative for lymph node invasion (67.7\%). Overall, family history was reported as follows: $33.7 \%$ had family history of breast cancer in at least one relative, $3.1 \%$ of ovarian cancer, $1.7 \%$ of male $\mathrm{BC}, 18.8 \%$ of other BRCA-associated cancers (prostate, pancreas and melanoma). Based on personal and familial history of cancer, $45.9 \%$ of the women enrolled met the National Comprehensive Cancer Network (NCCN) criteria for BRCA genetic testing (version 2.2017) [14]. Breast tumor and family history characteristics of the study population are presented in Table S2. Patients were enrolled from two major urban centers (San Juan in the North East and Ponce in the South), and their municipality of residence represented 53 of the 78 municipalities of Puerto Rico (Figure S1).

\subsection{BRCA1 Variants}

A total of 64 variants were identified in the BRCA1 gene, 48 of which are present at a frequency of less than 1\% in the 1000 Genomes PUR population (Puerto Ricans from Puerto Rico) or have not been reported in this population. Among those, there were the two positive controls from the Coriell Biorepository: NA13715 BRCA1 5382insC, NA14638 BRCA1 IVS5-11T>G. No additional known 
pathogenic variants were identified in this cohort (Table 1). In addition, six missense variants (Table 2) and four intronic variants (Table S3) were classified as variants of unknown significance (VUS) or had conflicting reports of pathogenicity in ClinVar [15]. The remaining variants are classified as benign or likely benign and are not reported.

Table 1. BRCA1 and BRCA2 pathogenic variants detected in Puerto Rican breast cancer patients.

\begin{tabular}{|c|c|c|c|c|c|c|c|c|}
\hline Gene/Exon & $\begin{array}{c}\text { AA } \\
\text { Change }\end{array}$ & $\begin{array}{c}\text { HGVS } \\
\text { Positions }^{1}\end{array}$ & $\begin{array}{c}\text { No } \\
\text { obs. }^{2}\end{array}$ & dbSNP & \multicolumn{4}{|c|}{ ExAC Frequencies $^{3}$} \\
\hline \multicolumn{9}{|l|}{$B R C A 1$} \\
\hline Exon 20 & Stop 1829 & $\begin{array}{c}\text { c.5263_5264insC } \\
\text { (g.41209082_41209083insG) }\end{array}$ & * & rs80357906 & $1.6 \times 10^{-4}$ & $2.8 \times 10^{-4}$ & 0 & 0 \\
\hline Exon 10 & Stop 599 & $\begin{array}{c}\text { c.1794_1798delATTTT } \\
\text { (g.32907409_32907413delATCTT) }\end{array}$ & 1 & NA & NA & NA & NA & NA \\
\hline Exon 11 & E1308X & $\begin{array}{c}\text { c.3922G }>\mathrm{T} \\
(\text { g.32912414G }>\mathrm{T})\end{array}$ & 8 & rs80358638 & NA & NA & NA & NA \\
\hline
\end{tabular}

${ }^{1}$ Refers to position on genome assembly hg19/GRCh37. ${ }^{2}$ Number of observations in the current study.

${ }^{3}$ Frequencies reported by the Exome Aggregation Consortium (ExAC) populations [15]. Afr African, Eur European (non-Finnish), Lat Latino, HVGS Human Genome Variation Society, NA not available. * Positive samples from Coriell Biorepository.

\subsection{BRCA2 Variants}

Out of the 102 variants identified in the BRCA2 gene, 79 had a reported frequency of less than $1 \%$ or were absent in the 1000 Genomes PUR sample. Two pathogenic variants (Table 1) were observed: a deletion of five base pairs resulting in a frameshift and a stop at position 599 of the BRCA2 protein (c.1794_1798delATTTT); and a nonsense mutation resulting in the change of a glutamate for a stop at position 1308 (c.3922G>T, rs80358638). Interestingly, the latter was recurrent in eight unrelated individuals from this study population. There were an additional eight missense variants (Table 2) and seven intronic variants (Table S3) with conflicting reports of pathogenicity in ClinVar or classified as VUS. Variants classified as benign or likely benign are not reported.

Table 2. $B R C A 1$ and $B R C A 2$ missense variants of uncertain significance detected in Puerto Rican breast cancer patients.

\begin{tabular}{|c|c|c|c|c|c|c|c|c|}
\hline \multirow{2}{*}{ Gene/Exon } & \multirow{2}{*}{$\begin{array}{c}\text { AA } \\
\text { Change }\end{array}$} & \multirow{2}{*}{$\begin{array}{c}\text { HGVS } \\
\text { Positions }^{1}\end{array}$} & \multirow{2}{*}{$\begin{array}{c}\text { No } \\
\text { obs. }^{2} \\
\end{array}$} & \multirow{2}{*}{ dbSNP } & \multicolumn{4}{|c|}{ ExAC Frequencies $^{3}$} \\
\hline & & & & & Overall & Eur & Afr & Lat \\
\hline \multicolumn{9}{|l|}{$B R C A 1$} \\
\hline Exon 11 & F1231L & c. $3691 \mathrm{~T}>\mathrm{C}(\mathrm{g} .41243857 \mathrm{~A}>\mathrm{G})$ & 1 & rs41293451 & $3.3 \times 10^{-5}$ & 0 & $3.8 \times 10^{-4}$ & 0 \\
\hline Exon 11 & $\mathrm{I} 1275 \mathrm{~V}$ & c. $3823 \mathrm{~A}>\mathrm{G}(\mathrm{g} .41243725 \mathrm{~T}>\mathrm{C})$ & 1 & rs 80357280 & $1.1 \times 10^{-4}$ & $7.5 \times 10^{-5}$ & 0 & $7.8 \times 10^{-4}$ \\
\hline Exon 13 & H1421R & c. $4262 \mathrm{~A}>\mathrm{G}(\mathrm{g} .41234516 \mathrm{~T}>\mathrm{C})$ & 1 & rs80357079 & NA & NA & NA & NA \\
\hline \multicolumn{9}{|l|}{$B R C A 2$} \\
\hline Exon 10 & $\mathrm{I} 283 \mathrm{~V}$ & c. $847 \mathrm{~A}>\mathrm{G}(\mathrm{g} .32906462 \mathrm{~A}>\mathrm{G})$ & 1 & rs80359097 & NA & NA & NA & NA \\
\hline Exon 10 & I488V & c. $1462 A>G($ g. $32907077 A>G)$ & 1 & NA & NA & NA & NA & NA \\
\hline Exon 10 & $\mathrm{Y} 600 \mathrm{H}$ & c. $1798 \mathrm{~T}>\mathrm{C}(\mathrm{g} .32907413 \mathrm{~T}>\mathrm{C})$ & 1 & rs75419644 & $4.9 \times 10^{-4}$ & 0 & $5.8 \times 10^{-3}$ & $1.7 \times 10^{-4}$ \\
\hline Exon 11 & K1058R & c. $3173 \mathrm{~A}>\mathrm{G}(\mathrm{g} \cdot 32911665 \mathrm{~A}>\mathrm{G})$ & 1 & rs431825302 & $1.7 \times 10^{-5}$ & 0 & 0 & $1.7 \times 10^{-4}$ \\
\hline Exon 11 & D1923A & C. $5768 \mathrm{~A}>\mathrm{C}(\mathrm{g} .32914260 \mathrm{~A}>\mathrm{C})$ & 1 & rs45491005 & $2.8 \times 10^{-4}$ & 0 & $3.2 \times 10^{-3}$ & $8.6 \times 10^{-5}$ \\
\hline
\end{tabular}

${ }^{1}$ Refers to position on genome assembly hg19/ GRCh37. ${ }^{2}$ Number of observations in the current study.

${ }^{3}$ Frequencies reported by the Exome Aggregation Consortium (ExAC) populations [16]. Afr African, Eur European (non-Finnish), Lat Latino, HVGS Human Genome Variation Society, NA not available. 


\subsection{Prediction of Functionality of Missense Variants of Uncertain Significance}

To evaluate the likelihood of pathogenicity of VUS, rare missense variants were submitted to in silico prediction models including Align-GVGD [17], Breast Cancer Gene Prior Probabilities of the Huntsman Cancer Institute (HCI BrCa) [18], Polyphen2 [19], SIFT [20] and Provean [21,22] (Table 3). In BRCA1, the H1421Y variant obtained a score of C15 on align GVGD and was predicted possibly damaging and damaging by Polyphen and SIFT. In BRCA2, K2950N had the highest GVGD score (C35) and was predicted to impact the protein function by three of the models tested ( $\mathrm{HCI} \mathrm{BrCa}$, Polyphen2, and SIFT). The majority of the remaining missense variants of uncertain significance were predicted benign by most or all models.

Table 3. In silico predictions of functionality for $B R C A 1$ and $B R C A 2$ missense variants of uncertain significance.

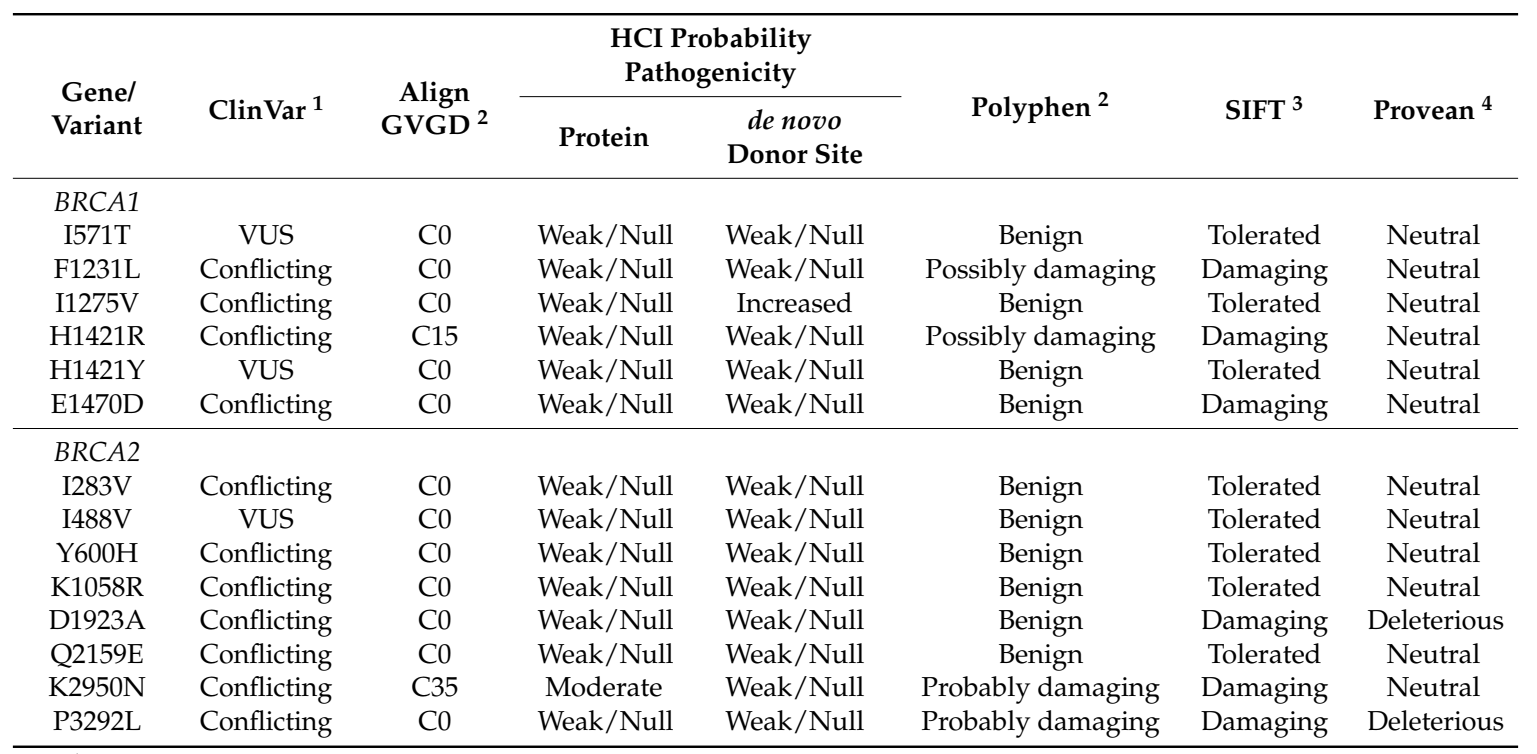

${ }^{1}$ Conflicting ClinVar classification refers to variants for which there were contradicting classifications as benign or uncertain significance depending on the source of the clinical report. ${ }^{2}$ Align GVGD grades were retrieved from the Huntsman Cancer Institute, University of Utah. ${ }^{3}$ Cutoff for the classification of a variant as damaging was a score $<0.05 .{ }^{4}$ Cutoff for the classification of a variant as deleterious was a score $<-2.5$. NA not available, VUS variant of uncertain significance, HCI Huntsman Cancer Institute.

\subsection{BRCA Mutation Prevalence and Clinical Characteristics of the Carriers}

A total of nine women were found to carry a known pathogenic mutation, which corresponds to a prevalence of $2.9 \%$ (95\% confidence interval (CI) $1.5-5.5 \%$ ) in this population of BC patients unselected for age of onset or family history. The proportion of BRCA carriers in BC cases diagnosed at or before 50 years of age was $5.2 \%$ (CI 2.4-10.8\%). When only patients that meet the NCCN criteria for BRCA testing [14] are selected (45.9\% of the cases), the prevalence increases to 5.6\% (CI 2.8-11.2\%). Interestingly, BRCA2 mutations represented $100 \%$ of the mutation carriers. Overall, carriers showed considerable variability in tumor pathology (Table 4). There was no clear bias in tumor type, site, size and characteristics of the cell surface receptors (Estrogen ER, Progesterone PR or Human epithelial growth factor, HER2 receptors). The family history characteristics of the carriers did not stand out with the exception of a stronger family history for male breast cancer, reported in second degree relatives of three BRCA2 E13908X carriers (Table 4). It is noteworthy that seven of the nine carriers met the NCCN criteria for BRCA testing. For the remaining two, insufficient data was available to determine whether there was a personal or family history of breast cancer sufficient to justify genetic testing. The patient UPR1024, BRCA2 c.1794_1798del5 carrier, was diagnosed at 52 years of age and did not report any family history of cancer. This individual would have been recommended for genetic testing only if triple negative (ER-, PR- and HER2-negative). PRI739, a BRCA2 E1308X carrier, was diagnosed at 53 and two first-degree relatives with a history of prostate cancer: his father was diagnosed at 
70 years and a brother who died at 47 years. Pathologies from those cancers were not available to determine whether the Gleason scores were $\geq 7$, in which case this patient would have met the criteria for $B R C A$ testing.

Table 4. Tumor pathology and family history characteristics of the deleterious BRCA variant carriers.

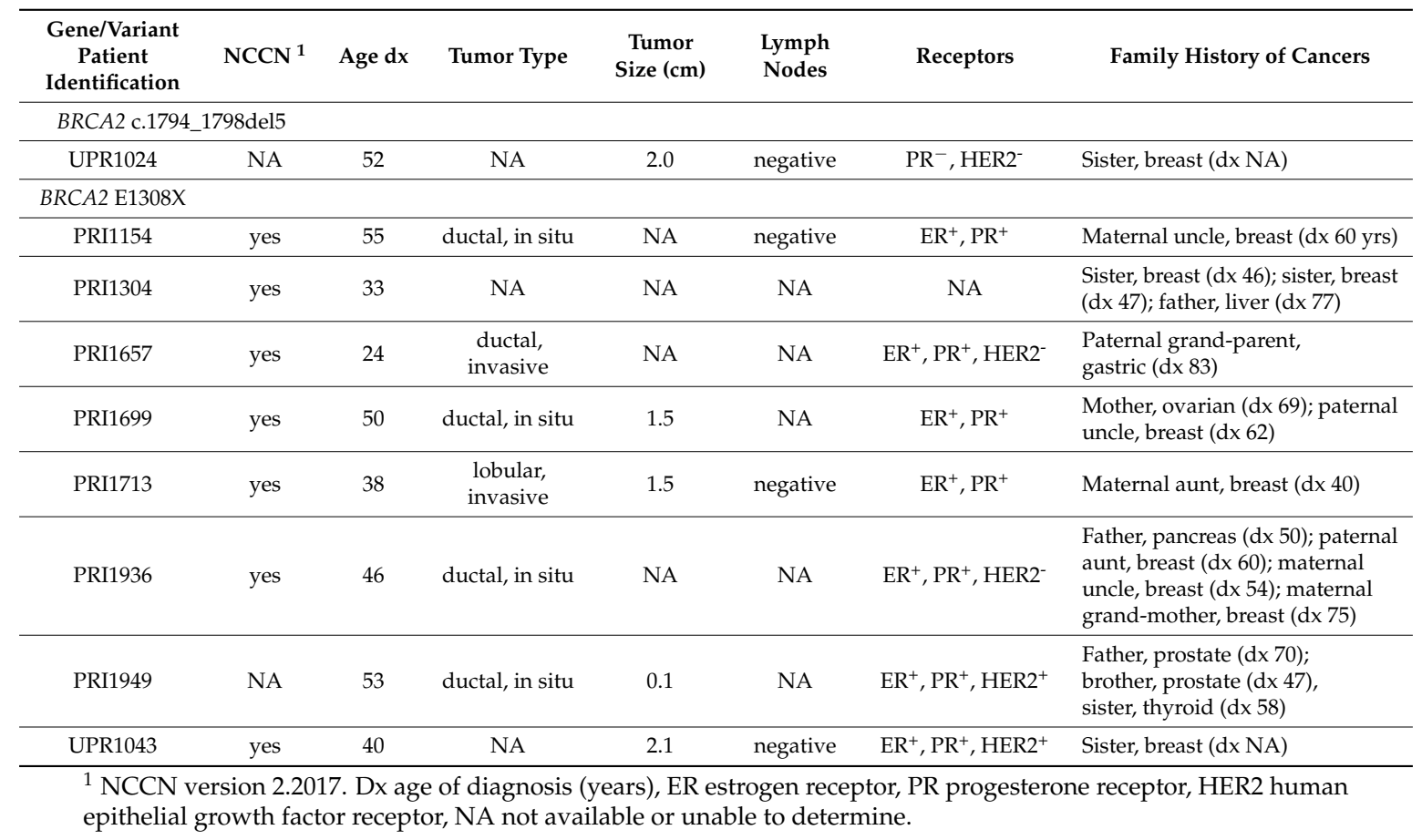

\subsection{Genomic Context in BRCA2 E1308X Carriers}

Given the high number of carriers of the BRCA2 E1308X mutation, haplotype analysis was conducted to assess whether the mutation has a common ancestral origin (Figure 1). For a subset of 207 study participants, including six of the eight BRCA2 E1308X carriers, genome-wide SNP array data was available to determine the haplotype in a $6 \mathrm{Mb}$ region around BRCA2. All six genotyped carriers of the BRCA2 E1308X pathogenic variant shared a common haplotype in a region spanning at least $1.74 \mathrm{Mb}$. This haplotype was absent in 199 non-carriers. Identity by state (IBS) analysis between all pairs of individuals using linkage disequilibrium pruned genome-wide markers confirmed that these carriers were not closely unrelated (identity by descent (IBD) PI-HAT for carrier pairs < 0.125). There was no obvious bias in the global ancestry proportions of BRCA2 E1308X carriers, although none of the carriers were within the upper end of the African ancestry distribution (Figure S2). All examined $B R C A 2$ E1308X carriers shared at least one chromosome of European origin in the BRCA2 region (Figure S2).

\section{Discussion}

We have characterized the $B R C A 1$ and $B R C A 2$ variants in 307 unselected breast cancer patients in Puerto Rico. The only published study on the BRCA mutation spectrum in Puerto Rico analyzed 23 high-risk patients and identified six unique mutations in 12 carriers. In total, seven unique pathogenic variants have been reported in Puerto Rico. In the current study, the proportion of BRCA carriers in unselected breast cancers cases was $2.9 \%$ (CI 1.5-5.5\%). This prevalence increased to $5.2 \%(2.4-10.8 \%)$ in cases diagnosed at or before 50 years of age, and to $5.6 \%$ (CI $2.8-11.2 \%$ ) in cases that met the NCCN criteria for BRCA testing [14]. The totality of the patients identified carried a pathogenic variant in $B R C A 2$, with the BRCA2 E1308X truncating variant accounting for $89 \%$ of carriers. 


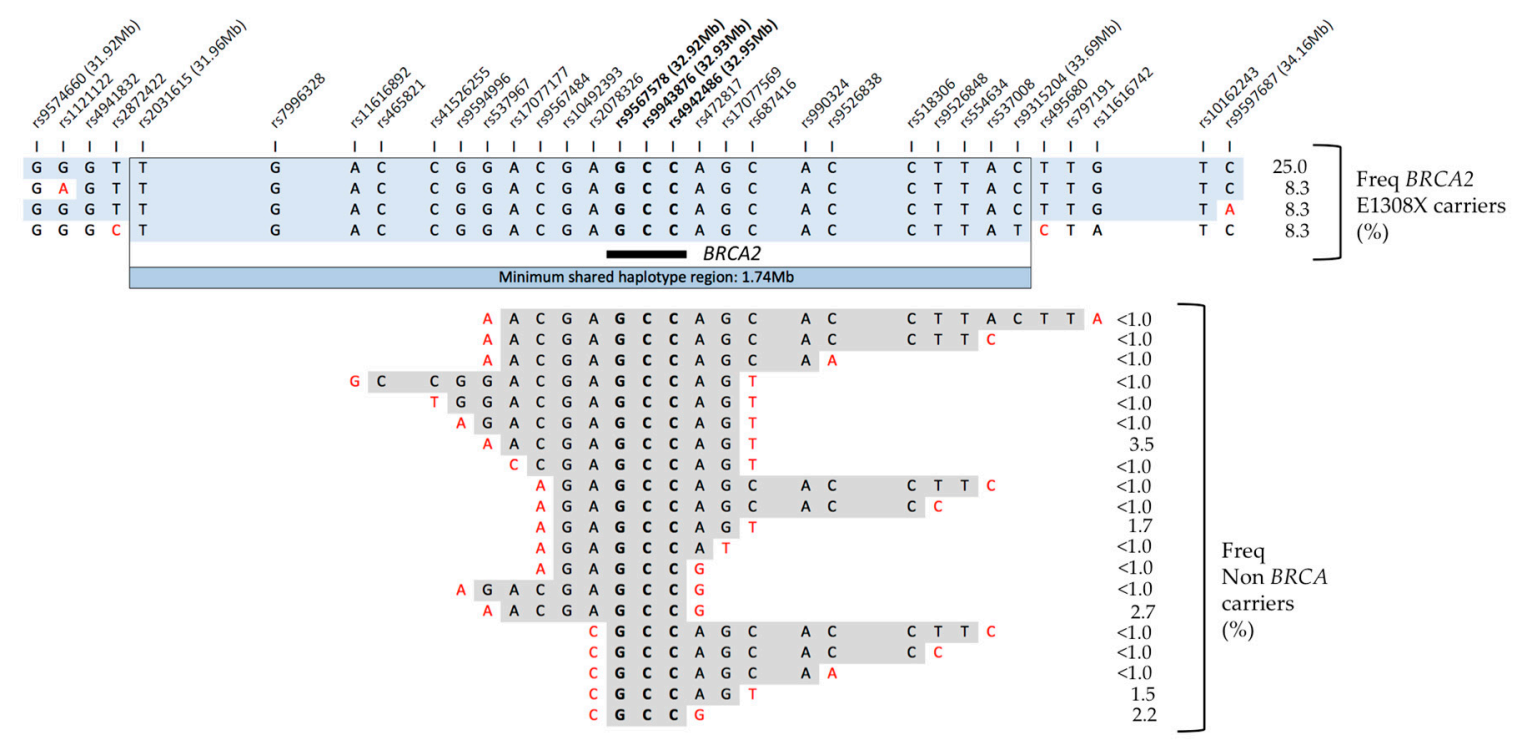

Figure 1. Shared haplotype and frequencies in a 2.24 Megabase $(\mathrm{Mb})$ region around the BRCA2 gene in carriers of the E1308X pathogenic variant $(n=6)$ and non-BRCA carriers $(n=201)$. A total of 73 markers were phased in a $2.6 \mathrm{Mb}$ region, but only 33 are represented. For non-BRCA carriers, only a fraction of the observed haplotypes are illustrated, representing the haplotypes that match those of the carriers within the BRCA2 gene.

Our data clearly establish the BRCA2 E1308X mutation as a common recurrent founder allele in Puerto Rico. Founder effects can occur when a colony is established from a small subset of individuals originating from a larger population. The genetic makeup of the Puerto Rico population is determined by its early colonial history where the Spanish, African and Taino peoples intermingled for several generations [23]. Previous studies have shown the occurrence of West Eurasian and North African founder haplotypes in Puerto Rico that are informative for specific ethnic groups that populated the island during colonization, and their frequencies have been shaped by random genetic drift [24]. The BRCA2 E1308X mutation was originally described in two independent families in Spain, each with three or more breast cancer cases, but without ovarian cancer. Duran et al. identified E1308X in a patient from Castilla-Leon, Spain, with an onset at 46 years of age, and three or more affected relatives [25]. In 410 Spanish breast cancer families and 214 isolated cases, BRCA2 E1308X was observed only once in a family with four breast cancer cases before age 50 and one after 50 [26]. Therefore, BRCA2 E1308X is present in Spain, but is not a common allele. Our haplotype analysis of $B R C A 2$ in E1308X carriers strongly supports a common origin, with the carriers sharing a haplotype in a region spanning at least 1.74 megabases around the gene. Consistent with the known origin of this mutation, local ancestry estimates show that all carriers examined shared at least one chromosome copy of European origin in the genomic region where BRCA2 is located. Interestingly, this variant was identified in patients residing in municipalities from the South of Puerto Rico (Peñuela, Ponce), the center of the island (Cidra, Naranjito), and in the Metropolitan area (Bayamon, San Juan), suggesting that the distribution of this variant within Puerto Rico is not restricted to a specific geographic area. This mutation was previously seen four times in 23 Puerto Rican high-risk subjects [13], and in a subject of Puerto Rican descent living in mainland US [27], and in US Hispanic/Latinos of unknown origin $[28,29]$. The combined data for Puerto Rico shows that this deleterious variant accounts for over $60 \%$ of the identified $B R C A 1 / 2$ carriers.

Founder mutations in the $B R C A 1 / B R C A 2$ genes have first been described in the Ashkenazi Jewish population, with BRCA1 185delAG, BRCA1 5382insC and BRCA2 6174delT representing $79 \%$ of the BRCA1/BRCA2 mutations found in this population [30]. Various founder mutations have also been reported in Latin American populations. The Ashkenazi founder mutations are recurrent in Argentina, in a population of known Jewish origin [31]. In Mexico, germline mutations 2805_2808delAGAT and 
3124_3133delAGCAATATTA in BRCA1, and 2639_2640delTG and 5114_5117delTAAA in BRCA2 are reported to be deleterious founder mutations [32]. In Colombia, carriers of the 3450del4 and A1708E in BRCA1 and 3034delACAA in BRCA2 shared common ancestors [33]. In Brazil, two mutations, 5382insC in BRCA1, 6633del5 and 156_157insAlu in BRCA2 are the most frequent [34]. This Alu insertion mutation has been identified in Portuguese families, suggesting a founder event of this mutation from Portuguese settlers in Brazil [35]. While some of these recurrent mutations have been observed in more than one country, the majority shows limited overlap [12]. Such observations confirm that populations from Latin America and the Caribbean are heterogeneous, resulting from unique combinations of ancestral genetic factors and historical events that have shaped the genetics of those populations today. In a context where access to genetic testing may be limited by economical resources and healthcare infrastructure, in some countries of Latin America, stepwise screening of recurrent mutations followed by complete assessment of $B R C A 1$ and $B R C A 2$ in negative cases has been proposed as a cost-effective strategy [36]. Nonetheless, available data indicate that if possible at all, such an approach should take into account the genetic diversity of the populations commonly referred to as Hispanic or Latinos.

As a result of the increased availability to genetic testing for hereditary cancers, and improved models for functional assessment [37], the proportion of unclassified variants in $B R C A 1 / B R C A 2$ has been progressively decreasing over time [29]. In this study, $6.8 \%(n=21)$ of the tested women were found to carry a missense variant of uncertain significance in $B R C A 1$ or $B R C A 2$, which is a rate lower than what has been previously reported for US Hispanics [29]. Yet, the clinical management of those variants presents a challenge. It has been shown to yield to over- or under- treatment [38], is of limited clinical utility for pre-symptomatic relatives, and can be associated with increased psychological distress [39]. While the clinical relevance of truncating frameshift and nonsense variants in the $B R C A 1 / 2$ genes is well understood, the classification of missense variants still represents a difficult task. Our recent work in a Puerto Rican cohort provided evidence against pathogenicity of the BRCA2 c.6937+594T $>G$ variant, therefore emphasizing the benefit to include diverse populations in examining evidence for variant classification [40].

For most of the cases that met the NCCN guidelines for BRCA-genetic testing, no pathogenic $B R C A$ variant was identified. Among those probands, some had family history strongly suggesting a genetic contribution such as early onset and multiple cases of $B C$, as well as ovarian cancer. In the recent past, testing of panels of susceptibility genes for hereditary cancer has replaced $B R C A 1 / 2$ testing. Pathogenic variants in PTEN, TP53, CHEK2, ATM, NBS1, RAD50, BRIP1 and PALB2, amongst others, have also been shown to confer moderate to high risk of breast cancer [41,42]. Genome-wide association studies (GWAS) have identified over a hundred loci associated with breast cancer risk, accounting for up to $12 \%$ of the familial risk attributed to common variants. Although the risk associated with individual loci is not elevated enough to inform clinical decisions, polygenic risk scores were proposed as risk stratification tools in population screening programs and targeted prevention [43]. Therefore, $B R C A 1 / 2$ testing is no longer sufficient to rule out the contribution of genetic factors to the cancers and it is possible that some of the patients for which no BRCA mutation was identified are carriers of a deleterious variant in another susceptibility gene or genes. Our preliminary work indicates that at least $8.3 \%$ of the high-risk $B C$ patients for which no $B R C A$ mutation is identified carry a pathogenic variant in another susceptibility gene [44].

Compared to our previous work in Puerto Rico, this study presents the advantage of screening for $B R C A$ mutations in a larger sample of $B C$ patients that have not been selected for family history or age of onset. It therefore presents more accurate estimates of the proportion of $B C$ cases attributed to $B R C A$ pathogenic variants. However, some limitations do remain. Given the sample size, it is unlikely that all the BRCA mutations underlying the breast and ovarian hereditary cancer syndrome in this population have been identified. In addition, a sampling is expected as a consequence of the recruitment design through clinics rather than the use of a census-based approach. The cohorts studied represent 58 out of the 78 municipalities of Puerto Rico, but some regions of the island are oversampled due to the 
proximity of the participating clinics. This is especially the case for the South of the Island, which was overrepresented in relation to population concentration in this area. There was also a lack of patients coming from the Western areas of Puerto Rico where one major urban center is located. Geographic variation in the ancestry proportions of the Puerto Rico population has been previously observed [23]. As a consequence, it is possible that a pathogenic $B R C A$ variant that would be more common within a restricted geographic area of Puerto Rico was not detected as a consequence of the sampling approach.

\section{Materials and Methods}

\subsection{Study Population}

The study population consists of 232 BC patients recruited through the Ponce Research Institute (PRI) of Ponce Health Sciences University, and 75 patients from the University of Puerto Rico (UPR) Comprehensive Cancer Center. Patients undergoing BRCA analysis and recruited through the PRI are a subset of a larger cohort, which has been described previously [45]. In brief, between 2006 and 2012, in participating clinics, patients were approached by the research nurse or study coordinator and offered to participate in the study. Patients were recruited at the moment of initial diagnosis, were not selected for family history and were diagnosed at any age. Patient recruitment and counseling was approved by IRBs at the Ponce Research Institute (IRB\#070918-JD), the University of Puerto Rico Medical Sciences Campus (IRB\#A1810111), and under an exemption from the National Institutes of Health (NIH) Office of Human Subjects Protection (Exemption \#5252AA) for coded samples sent to the National Cancer Institute (NCI) for sequencing. Cases were identified in oncology and surgery clinics located in the Metropolitan area and the South of the Island but who serve patients from all over the island. Inclusion criteria for cases were patients who (1) were 21 years or older, and (2) were recently diagnosed histopathologically with primary BC. Cases that had been previously treated for cancer at another site were excluded from this protocol. Participants completed a standard questionnaire regarding their demographic information, hormonal and pregnancy history and family history of cancer and a blood sample was drawn for DNA extraction. Additionally, a tumor pathology report was obtained. DNA from three known BRCA pathogenic carriers was included as positive controls for sequencing, two of which were provided by the Corriell Cell Repository (NA13715 BRCA1 5382insC, NA14638 BRCA1 IVS5-11T>G) and from the Ponce Research Institute (BRCA2 del exon 1-2).

\subsection{Sample Preparation and BRCA1/2 Sequencing}

Genomic DNA was extracted from blood lymphocytes or whole blood using QIAamp and Paxgene DNA kits (QIAGEN, Germantown, MD USA), respectively. The concentration of DNA was measured using the Nano Drop 2000 spectrophotometer (Thermo Fisher Scientific, Waltham, MA, USA). Libraries were prepared using the Ion Ampliseq Library kit 2.0 (Life Technologies, Calrlsbad, CA, USA) according to the manufacturer's protocol using $15 \mathrm{ng}$ genomic DNA. Multiplex PCR was performed with Ion AmpliSeq BRCA1 and BRCA2 Community Panel (Life Technologies), which consists of 163 primer pairs in three pools and was designed to capture all BRCA1/BRCA2 coding exons and exon-intron junctions $(24,143 \mathrm{bp})$. Following adaptor and barcode ligation, libraries were pooled and amplified by emulsion PCR using the OneTouch2 system and Ion Xpress template kit (Life Technologies). Ion Sphere particles were enriched using the E/S module and sequenced on PGM using a 316 chip (Life Technologies). Full screening of BRCA1 for the detection of large rearrangements using multiplex ligation-dependent probe amplification (MLPA) was performed according to the manufacturer's protocol (MRC Holland, Amsterdam, The Netherlands).

\subsection{Variant, Filtering and Annotation}

The sequence data were processed using standard Ion Torrent Suite Software with standard parameters [27]. Variants passing quality controls and filtering were visually confirmed using the Integrative Genomics Viewer (IGV) [46]. Rare variants (with a reported frequency $<1 \%$ or absent from 
the 1000 Genomes Puerto Ricans from Puerto Rico (PUR)) were classified according to their position in the gene and annotated using ClinVar [15]. Frequencies from the Exome Aggregation Consortium (ExAC) were also reported [16]. For missense variants, predictions of pathogenicity were generated using Align-GVGD [17], Breast Cancer Gene Prior Probabilities of the Huntsman Cancer Institute (HCI BrCa) [18], Polyphen2 [19], SIFT [20] and Provean [21,22].

\subsection{Ancestry Analyses}

Global ancestry proportions of each participant were estimated using a panel of 106 ancestry informative SNPs that can discriminate indigenous American, African, and European ancestry, and distributed across all 22 autosomal chromosomes. Genotyping of the 106 ancestry informative markers for all samples was done by using a multiplex PCR using a Sequenom analyzer. The SNP panel, primers and reaction conditions have been previously described [47]. For each individual, respective proportions of European, African and Native American ancestry were estimated using ADMIXTURE [48]. In pathogenic variant carriers, local ancestry at the site of the genes of interest was extracted from whole genome local ancestry estimates (available for 207 samples). These local ancestry estimates were obtained from a subset 67,000 SNPs genotyped on an Affymetrix Axiom UK Biobank Array. Genotypes were phased using Shape-IT [49] and locus-specific ancestry was determined by RFMix [50].

\subsection{Haplotype Analysis}

In genomic regions around recurrent pathogenic variants, haplotypes were determined using a subset of markers from the 67,000 SNPs genotyped on an Affymetrix Axiom UK Biobank Array (73 SNPS in a 2.25 Megabases $(\mathrm{Mb})$ genomic interval around BRCA2, GRCh37/hg19 chr13:31.92-34.16 Mb) and phased using PHASE v2.1.1 [51] using the $-\mathrm{x} 5$ flag.

\subsection{Statistical Analysis}

All statistical analyses were conducted with $\mathrm{R}$ version 3.2.1 implemented in $\mathrm{R}$ Studio [52]. Differences in frequency distributions were calculated by Pearson Chi-square $\chi^{2}$ test.

\section{Conclusions}

We have demonstrated that in unselected $\mathrm{BC}$ cases from Puerto Rico, the prevalence of the BRCA1 and $B R C A 2$ mutations is $2.9 \%$. BRCA2 is the predominant gene mutated in breast cancer patients in this population, with a single mutation, E1308X accounting for $88 \%$ of the alleles. Further screening of this mutation could aid in the early diagnosis prevention and reduction of mortality of breast cancer.

Supplementary Materials: The following are available online at http://www.mdpi.com/2072-6694/10/11/ 419/s1, Table S1: demographic, reproductive and hormonal characteristics of the study population; Table S2: breast tumor pathology and family history characteristics of the study population; Table S3: BRCA1 and BRCA2 intronic variants of uncertain significance; Figure S1: geographic distribution of the study population; Figure S2: global ancestry proportion of the study population and local ancestry at the BRCA2 locus in carriers of the E1308X mutation.

Author Contributions: Conceptualization, A.P.O., T.K.O., M.E., M.D. and J.D.; Investigation, H.J.D.-Z., A.P.O., L.G., K.J., C.M.P., N.A.; Formal analysis: H.J.D.-Z., J.D.; Resources, A.P.O., C.M.P., E.M., M.E., J.L.M., M.D.; Data Curation, A.P.O., J.D.; Writing-Original Draft Preparation, H.J.D.-Z., A.P.O., M.D., J.D.; Writing-Review \& Editing, L.G., C.M.P., E.M., M.D., J.D.; Visualization, H.J.D.-Z., J.D.; Supervision, A.P.O., K.J., C.M.P., M.D., J.D.; Funding Acquisition: A.P.O., C.M.P., E.M., J.L.M., J.D.

Funding: This work was supported by grants of the National Institute of Health (NIH) National Cancer Institute (NCI) (The Ponce Health Sciences University and Moffitt Cancer Center Partnership for Excellence in Cancer Research U54 grant CA163071 for BRCA analysis and 1SC1CA182845 for ancestry and haplotype analyses) with the technical support of the Ponce Research Institute Molecular and Genomics Core (M.A.G.I.C) (NIH-National Institute on Minority Health and Health Disparities (NIMHD) MD007579), and the intramural research program of the Division of Cancer Epidemiology and Genetics, National Cancer Institute, National Institutes of Health. Patient recruitment was supported by grants from the NIH-National Institute of General Medical Sciences (NIGMS) (S06-GM008239 and 9SC1CA182846). Study also partially supported by The University of Puerto Rico 
and The University of Texas MD Anderson Cancer Center Partnership for Excellence in Cancer Research U54 grant CA096297/CA096300 from the NCI, NIH (San Juan cohort). H Diaz-Zabala received a fellowship from NIH-NIGMS (R25GM082406).

Acknowledgments: The authors are grateful to all the women who participated in this study. We also want to thank the clinical staff at recruitment sites and Wanda Vargas at Ponce Research Institute.

Conflicts of Interest: The authors declare no conflict of interest. The founding sponsors had no role in the design of the study; in the collection, analyses, or interpretation of data; in the writing of the manuscript, and in the decision to publish the results.

\section{References}

1. Miki, Y.; Swensen, J.; Shattuck-Eidens, D.; Futreal, P.A.; Harshman, K.; Tavtigian, S.; Liu, Q.; Cochran, C.; Bennett, L.M.; Ding, W.; et al. A strong candidate for the breast and ovarian cancer susceptibility gene BRCA1. Science 1994, 266, 66-71. [CrossRef] [PubMed]

2. Wooster, R.; Bignell, G.; Lancaster, J.; Swift, S.; Seal, S.; Mangion, J.; Collins, N.; Gregory, S.; Gumbs, C.; Micklem, G.; et al. Identification of the breast cancer susceptibility gene BRCA2. Nature 1995, 378, 789-792. [CrossRef] [PubMed]

3. Warner, E.; Plewes, D.B.; Hill, K.A.; Causer, P.A.; Zubovits, J.T.; Jong, R.A.; Cutrara, M.R.; DeBoer, G.; Yaffe, M.J.; Messner, S.J.; et al. Surveillance of BRCA1 and BRCA2 mutation carriers with magnetic resonance imaging, ultrasound, mammography, and clinical breast examination. JAMA 2004, 292, 1317-1325. [CrossRef] [PubMed]

4. King, M.C.; Wieand, S.; Hale, K.; Lee, M.; Walsh, T.; Owens, K.; Tait, J.; Ford, L.; Dunn, B.K.; Costantino, J.; et al. Tamoxifen and breast cancer incidence among women with inherited mutations in BRCA1 and BRCA2: National Surgical Adjuvant Breast and Bowel Project (NSABP-P1) Breast Cancer Prevention Trial. JAMA 2001, 286, 2251-2256. [CrossRef] [PubMed]

5. Vogel, V.G.; Costantino, J.P.; Wickerham, D.L.; Cronin, W.M.; Cecchini, R.S.; Atkins, J.N.; Bevers, T.B.; Fehrenbacher, L.; Pajon, E.R.; Wade, J.L., 3rd; et al. Update of the National Surgical Adjuvant Breast and Bowel Project Study of Tamoxifen and Raloxifene (STAR) P-2 Trial: Preventing breast cancer. Cancer Prev. Res. 2010, 3, 696-706. [CrossRef] [PubMed]

6. Rebbeck, T.R.; Friebel, T.; Lynch, H.T.; Neuhausen, S.L.; van't Veer, L.; Garber, J.E.; Evans, G.R.; Narod, S.A.; Isaacs, C.; Matloff, E.; et al. Bilateral prophylactic mastectomy reduces breast cancer risk in BRCA1 and BRCA2 mutation carriers: The PROSE Study Group. J. Clin. Oncol. 2004, 22, 1055-1062. [CrossRef] [PubMed]

7. Domchek, S.M.; Friebel, T.M.; Singer, C.F.; Evans, D.G.; Lynch, H.T.; Isaacs, C.; Garber, J.E.; Neuhausen, S.L.; Matloff, E.; Eeles, R.; et al. Association of risk-reducing surgery in BRCA1 or BRCA2 mutation carriers with cancer risk and mortality. JAMA 2010, 304, 967-975. [CrossRef] [PubMed]

8. Schwartz, M.D.; Lerman, C.; Brogan, B.; Peshkin, B.N.; Halbert, C.H.; DeMarco, T.; Lawrence, W.; Main, D.; Finch, C.; Magnant, C.; et al. Impact of $B R C A 1 / B R C A 2$ counseling and testing on newly diagnosed breast cancer patients. J. Clin. Oncol. 2004, 22, 1823-1829. [CrossRef] [PubMed]

9. Weitzel, J.N.; McCaffrey, S.M.; Nedelcu, R.; MacDonald, D.J.; Blazer, K.R.; Cullinane, C.A. Effect of genetic cancer risk assessment on surgical decisions at breast cancer diagnosis. Arch. Surg. 2003, 138, 1323-1328. [CrossRef] [PubMed]

10. Cortesi, L.; Razzaboni, E.; Toss, A.; De Matteis, E.; Marchi, I.; Medici, V.; Tazzioli, G.; Andreotti, A.; De Santis, G.; Pignatti, M.; et al. A rapid genetic counselling and testing in newly diagnosed breast cancer is associated with high rate of risk-reducing mastectomy in BRCA1/2-positive Italian women. Ann. Oncol. 2014, 25, 57-63. [CrossRef] [PubMed]

11. Galanter, J.M.; Fernandez-Lopez, J.C.; Gignoux, C.R.; Barnholtz-Sloan, J.; Fernandez-Rozadilla, C.; Via, M.; Hidalgo-Miranda, A.; Contreras, A.V.; Figueroa, L.U.; Raska, P.; et al. Development of a panel of genome-wide ancestry informative markers to study admixture throughout the Americas. PLoS Genet. 2012, 8, e1002554. [CrossRef] [PubMed]

12. Dutil, J.; Golubeva, V.A.; Pacheco-Torres, A.L.; Diaz-Zabala, H.J.; Matta, J.L.; Monteiro, A.N. The spectrum of BRCA1 and BRCA2 alleles in Latin America and the Caribbean: A clinical perspective. Breast Cancer Res. Treat. 2015, 154, 441-453. [CrossRef] [PubMed] 
13. Dutil, J.; Colon-Colon, J.L.; Matta, J.L.; Sutphen, R.; Echenique, M. Identification of the prevalent BRCA1 and BRCA2 mutations in the female population of Puerto Rico. Cancer Genet. 2012, 205, 242-248. [CrossRef] [PubMed]

14. National Comprehensive Cancer Network. NCCN Clinical Practice Guidelines in Oncology (NCCN Guidelines): Genetic/Familial High-Risk Assessment: Breast and Ovarian. Version 2. 2017. Available online: http:/ / www.nccn.org/ (accessed on 10 August 2017).

15. Landrum, M.J.; Lee, J.M.; Benson, M.; Brown, G.; Chao, C.; Chitipiralla, S.; Gu, B.; Hart, J.; Hoffman, D.; Hoover, J.; et al. ClinVar: Public archive of interpretations of clinically relevant variants. Nucleic Acids Res. 2016, 44, D862-D868. [CrossRef] [PubMed]

16. Lek, M.; Karczewski, K.J.; Minikel, E.V.; Samocha, K.E.; Banks, E.; Fennell, T.; O'Donnell-Luria, A.H.; Ware, J.S.; Hill, A.J.; Cummings, B.B.; et al. Exome Aggregation Consortium. Analysis of protein-coding genetic variation in 60,706 humans. Nature 2016, 536, 285-291. [CrossRef] [PubMed]

17. Tavtigian, S.V.; Deffenbaugh, A.M.; Yin, L.; Judkins, T.; Scholl, T.; Samollow, P.B.; de Silva, D.; Zharkikh, A.; Thomas, A. Comprehensive statistical study of 452 BRCA1 missense substitutions with classification of eight recurrent substitutions as neutral. J. Med. Genet. 2006, 43, 295-305. [CrossRef] [PubMed]

18. Huntsman Cancer Institute (HCI). Breast Cancer Genes Prior Probabilities. Available online: http://priors. hci.utah.edu/PRIORS/index.php/ (accessed on 20 June 2017).

19. Adzhubei, I.A.; Schmidt, S.; Peshkin, L.; Ramensky, V.E.; Gerasimova, A.; Bork, P.; Kondrashov, A.S.; Sunyaev, S.R. A method and server for predicting damaging missense mutations. Nat. Methods 2010, 7, $248-249$. [CrossRef] [PubMed]

20. Sim, N.L.; Kumar, P.; Hu, J.; Henikoff, S.; Schneider, G.; Ng, P.C. SIFT web server: Predicting effects of amino acid substitutions on proteins. Nucleic Acids Res. 2012, 40, W452-W457. [CrossRef] [PubMed]

21. Choi, Y.; Sims, G.E.; Murphy, S.; Miller, J.R.; Chan, A.P. Predicting the functional effect of amino acid substitutions and indels. PLoS ONE 2012, 7, e46688. [CrossRef] [PubMed]

22. Choi, Y.; Chan, A.P. PROVEAN web server: A tool to predict the functional effect of amino acid substitutions and indels. Bioinformatics 2015, 31, 2745-2747. [CrossRef] [PubMed]

23. Via, M.; Gignoux, C.R.; Roth, L.A.; Fejerman, L.; Galanter, J.; Choudhry, S.; Toro-Labrador, G.; Viera-Vera, J.; Oleksyk, T.K.; Beckman, K.; et al. History shaped the geographic distribution of genomic admixture on the island of Puerto Rico. PLoS ONE 2011, 6, e16513. [CrossRef] [PubMed]

24. Díaz-Zabala, H.J.; Nieves-Colón, M.A.; Martínez-Cruzado, J.C. A Mainly Circum-Mediterranean Origin for West Eurasian and North African mtDNAs in Puerto Rico with Strong Contributions from the Canary Islands and West Africa. Hum. Biol. 2017, 89, 125-155. [CrossRef] [PubMed]

25. Duran, M.; Esteban-Cardeñosa, E.; Velasco, E.; Infante, M.; Miner, C. Mutational analysis of BRCA2 in Spanish breast cancer patients from Castilla-Leon: Identification of four novel truncating mutations. Hum. Mutat. 2003, 21, 448. [CrossRef] [PubMed]

26. Díez, O.; Osorio, A.; Durán, M.; Martinez-Ferrandis, J.I.; de la Hoya, M.; Salazar, R.; Vega, A.; Campos, B.; Rodríguez-López, R.; Velasco, E.; et al. Analysis of BRCA1 and BRCA2 genes in Spanish breast/ovarian cancer patients: A high proportion of mutations unique to Spain and evidence of founder effects. Hum. Mutat. 2003, 22, 301-312. [CrossRef] [PubMed]

27. Dean, M.; Boland, J.; Yeager, M.; Im, K.M.; Garland, L.; Rodriguez-Herrera, M.; Perez, M.; Mitchell, J.; Roberson, D.; Jones, K.; et al. Addressing health disparities in Hispanic breast cancer: Accurate and inexpensive sequencing of BRCA1 and BRCA2. Gigascience 2015, 4, 50. [CrossRef] [PubMed]

28. Vogel, K.J.; Atchley, D.P.; Erlichman, J.; Broglio, K.R.; Ready, K.J.; Valero, V.; Amos, C.I.; Hortobagyi, G.N.; Lu, K.H.; Arun, B. BRCA1 and BRCA2 genetic testing in Hispanic patients: Mutation prevalence and evaluation of the BRCAPRO risk assessment model. J. Clin. Oncol. 2007, 25, 4635-4661. [CrossRef] [PubMed]

29. Hall, M.J.; Reid, J.E.; Burbidge, L.A.; Pruss, D.; Deffenbaugh, A.M.; Frye, C.; Wenstrup, R.J.; Ward, B.E.; Scholl, T.A.; Noll, W.W. BRCA1 and BRCA2 mutations in women of different ethnicities undergoing testing for hereditary breast-ovarian cancer. Cancer 2009, 115, 2222-2233. [CrossRef] [PubMed]

30. Frank, T.S.; Deffenbaugh, A.M.; Reid, J.E.; Hulick, M.; Ward, B.E.; Lingenfelter, B.; Gumpper, K.L.; Scholl, T.; Tavtigian, S.V.; Pruss, D.R.; et al. Clinical characteristics of individuals with germline mutations in BRCA1 and BRCA2: Analysis of 10,000 individuals. J. Clin. Oncol. 2002, 20, 1480-1490. [CrossRef] [PubMed] 
31. Solano, A.R.; Aceto, G.M.; Delettieres, D.; Veschi, S.; Neuman, M.I.; Alonso, E.; Chialina, S.; Chacón, R.D.; Renato, M.C.; Podestá, E.J. BRCA1 and BRCA2 analysis of Argentinean breast/ovarian cancer patients selected for age and family history highlights a role for novel mutations of putative south-American origin. SpringerPlus 2012, 1, 20. [CrossRef] [PubMed]

32. Vaca-Paniagua, F.; Alvarez-Gomez, R.M.; Fragoso-Ontiveros, V.; Vidal-Millan, S.; Herrera, L.A.; Cantú, D.; Bargallo-Rocha, E.; Mohar, A.; López-Camarillo, C.; Pérez-Plasencia, C. Full-exon pyrosequencing screening of BRCA germline mutations in Mexican women with inherited breast and ovarian cancer. PLoS ONE 2012, 7, e37432. [CrossRef] [PubMed]

33. Torres, D.; Rashid, M.U.; Gil, F.; Umana, A.; Ramelli, G.; Robledo, J.F.; Tawil, M.; Torregrosa, L.; Briceno, I.; Hamann, U. High proportion of BRCA1/2 founder mutations in Hispanic breast/ovarian cancer families from Colombia. Breast Cancer Res. Treat. 2007, 103, 225-232. [CrossRef] [PubMed]

34. Gomes, M.C.; Costa, M.M.; Borojevic, R.; Monteiro, A.N.; Vieira, R.; Koifman, S.; Koifman, R.J.; Li, S.; Royer, R.; Zhang, S.; et al. Prevalence of BRCA1 and BRCA2 mutations in breast cancer patients from Brazil. Breast Cancer Res. Treat. 2007, 103, 349-353. [CrossRef] [PubMed]

35. Peixoto, A.; Santos, C.; Pinheiro, M.; Pinto, P.; Soares, M.J.; Rocha, P.; Gusmão, L.; Amorim, A.; van der Hout, A.; Gerdes, A.M.; et al. International distribution and age estimation of the Portuguese BRCA2 c.156_157insAlu founder mutation. Breast Cancer Res. Treat. 2011, 127, 671-679. [CrossRef] [PubMed]

36. Weitzel, J.N.; Clague, J.; Martir-Negron, A.; Ogaz, R.; Herzog, J.; Ricker, C.; Jungbluth, C.; Cina, C.; Duncan, P.; Unzeitig, G.; et al. Prevalence and type of BRCA mutations in Hispanics undergoing genetic cancer risk assessment in the southwestern United States: A report from the Clinical Cancer Genetics Community Research Network. J. Clin. Oncol. 2013, 31, 210-216. [CrossRef] [PubMed]

37. Hart, S.N.; Hoskin, T.; Shimelis, H.; Moore, R.M.; Feng, B.; Thomas, A.; Lindor, N.M.; Polley, E.C.; Goldgar, D.E.; Iversen, E.; et al. Comprehensive annotation of BRCA1 and BRCA2 missense variants by functionally validated sequence-based computational prediction models. Genet. Med. 2018. [CrossRef] [PubMed]

38. Lindor, N.M.; Goldgar, D.E.; Tavtigian, S.V.; Plon, S.E.; Couch, F.J. BRCA1/2 sequence variants of uncertain significance: A primer for providers to assist in discussions and in medical management. Oncologist 2013, 18, 518-524. [CrossRef] [PubMed]

39. U.S. Preventive Task Force. Risk Assessment, genetic counseling, and genetic testing for BRCA-related cancer in women: Recommendation statement. Am. Fam. Phys. 2015, 91. Available online: https://www. aafp.org/afp/2015/0115/od1.html/ (accessed on 8 August 2018).

40. Dutil, J.; Godoy, L.; Rivera-Lugo, R.; Arroyo, N.; Albino, E.; Negrón, L.; Monteiro, A.N.; Matta, J.L.; Echenique, M. No Evidence for the pathogenicity of the BRCA2 c.6937+594T>G deep intronic variant: A case-control analysis. Genet. Test. Mol. Biomark. 2018, 22, 85-89. [CrossRef] [PubMed]

41. Walsh, T.; Casadei, S.; Lee, M.K.; Pennil, C.C.; Nord, A.S.; Thornton, A.M.; Roeb, W.; Agnew, K.J.; Stray, S.M.; Wickramanayake, A.; et al. Mutations in 12 genes for inherited ovarian, fallopian tube, and peritoneal carcinoma identified by massively parallel sequencing. Proc. Natl. Acad. Sci. USA 2011, 108, 18032-18037. [CrossRef] [PubMed]

42. Easton, D.F.; Pharoah, P.D.P.; Antoniou, A.C.; Tischkowitz, M.; Tavtigian, S.V.; Nathanson, K.L.; Devilee, P.; Meindl, A.; Couch, F.J.; Southey, M.; et al. Gene-panel sequencing and the prediction of breast cancer risk. N. Engl. J. Med. 2015, 372, 2243-2257. [CrossRef] [PubMed]

43. Wacholder, S.; Hartge, P.; Prentice, R.; Garcia-Closas, M.; Feigelson, H.S.; Diver, W.R.; Thun, M.J.; Cox, D.G.; Hankinson, S.E.; Kraft, P.; et al. Performance of common genetic variants in breast-cancer risk models. N. Engl. J. Med. 2010, 362, 986-993. [CrossRef] [PubMed]

44. Dutil, J.; Teer, J.K.; Golubeva, V.; Yoder, S.; Tong, W.L.; Arroyo, N.; Echenique, M.; Matta, J.L.; Monterio, A.N. Germline vaiants in cancer genes in high-risk non-BRCA patients from Puerto Rico. In preparation.

45. Matta, J.; Echenique, M.; Negron, E.; Morales, L.; Vargas, W.; Gaetan, F.S.; Lizardi, E.R.; Torres, A.; Rosado, J.O.; Bolaños, G.; et al. The association of DNA Repair with breast cancer risk in women. A comparative observational study. BMC Cancer 2012, 12, 490. [CrossRef] [PubMed]

46. Thorvaldsdóttir, H.; Robinson, J.T.; Mesirov, J.P. Integrative Genomics Viewer (IGV): High-performance genomics data visualization and exploration. Brief. Bioinform. 2013, 14, 178-192. [CrossRef] [PubMed] 
47. Fejerman, L.; John, E.M.; Huntsman, S.; Beckman, K.; Choudhry, S.; Perez-Stable, E.; Burchard, E.G.; Ziv, E. Genetic ancestry and risk of breast cancer among U.S. Latinas. Cancer Res. 2008, 68, 9723-9728. [CrossRef] [PubMed]

48. Alexander, D.H.; Novembre, J.; Lange, K. Fast model-based estimation of ancestry in unrelated individuals. Genome Res. 2009, 19, 1655-1664. [CrossRef] [PubMed]

49. Delaneau, O.; Coulonges, C.; Zagury, J.-F. Shape-IT: New rapid and accurate algorithm for haplotype inference. BMC Bioinformat. 2008, 9, 540. [CrossRef] [PubMed]

50. Maples, B.K.; Gravel, S.; Kenny, E.E.; Bustamante, C.D. RFMix: A discriminative modeling approach for rapid and robust local-ancestry inference. Am. J. Hum. Genet. 2013, 93, 278-288. [CrossRef] [PubMed]

51. Stephens, M.; Smith, N.J.; Donnelly, P. A new statistical method for haplotype reconstruction from population data. Am. J. Hum. Genet. 2001, 68, 978-989. [CrossRef] [PubMed]

52. R Studio Team. RStudio: Integrated Development for R; RStudio, Inc.: Boston, MA, USA. Available online: http:/ / www.rstudio.com/ (accessed on 10 August 2017).

(C) 2018 by the authors. Licensee MDPI, Basel, Switzerland. This article is an open access article distributed under the terms and conditions of the Creative Commons Attribution (CC BY) license (http:/ / creativecommons.org/licenses/by/4.0/). 